\title{
A Study on the Aesthetic Value of Texts in Turkish Language Textbooks
}

\author{
Salim Pilav ${ }^{1}$ \\ ${ }^{1}$ Assistant Professor, Department of Turkish Teaching, Kırıkale Univesity, Kırıkkale, Turkey \\ Correspondence: Salim Pilav, Assistant Professor, Department of Turkish Teaching, Kırıkkale Univesity, Kırıkkale, \\ Turkey.
}

Received: October 10, 2016

doi:10.11114/jets.v4i12.1917
Accepted: November 9, 2016

Online Published: November 14, 2016

URL: http://dx.doi.org/10.11114/jets.v4i12.1917

\begin{abstract}
One of the main objectives of education is to enable the individual to obtain an aesthetic perspective by using language. It is through such classes as Turkish Language and Literature that students not only explore skill-based aspects of Turkish language but also get acquainted with its artistic properties. Therefore, the texts used in these classes should provide students with aesthetic taste and opportunity to sense the artistic aspects of the language. In this study, aesthetic properties of the texts in Turkish textbooks at secondary school were evaluated. The study examines whether and to what extent these texts are effective in developing students' aesthetic tastes. One poem and one narrative from a textbook at each grade were randomly chosen and evaluated in accordance with the criteria of aesthetic pleasure. It is concluded that the texts in secondary school textbooks are insufficient in providing students with aesthetic values; several suggestions were made in order to develop students' aesthetic pleasures.
\end{abstract}

Keywords: aesthetic taste/pleasure, Turkish textbooks; text selection, teaching Turkish, education

\section{Introduction}

"Aesthetics" and "beauty" are two terms identified with each other. While aesthetics questions what beauty is, it always attempts to reach out to the beautiful. A work (of art), which could be assessed as valuable, from an aesthetical point of view, is characterized with the term "beautiful". In this respect, anything beautiful is of interest to the aesthetics. The term was first used in today's context by Alexander Baumgarten. In his work "Meditationes philosophicae de nonnullis and poem a pertinentibus" he has used the term "aesthetics" to determine a tangible field of knowledge where meaning content is transmitted in an emotional format and he declared that emotions were determinant in judgements on beauty (Bozkurt, 1995).

According to Nietzsche, aesthetics is a teaching/discipline trying to reconcile the art with life by choosing an effective vision. According to Hegel, aesthetics is all kinds of philosophical reflections made on art. In other words, sensibility and aesthetics is the same thing (Bozkurt, 1995). In general, aesthetics is related with reactions of human beings expressed by the terms of beautiful" and "ugly". However, the scope of these terms are indefinite and their meanings are subjective and relative (Bozkurt, 1995).

Since aesthetics is a discipline scrutinizing the beauty, the concept of "aesthetic taste" means "enjoying the beautiful". Aesthetic taste effects and is affected by the beautiful. Indeed, in order to be able to term an object as "beautiful", it is necessary that it arouses an aesthetic feeling over the person. In this respect, certain targets are being set in education programs for development of person's sense of aesthetic taste.

The related special purposes set in Turkish Language Teaching Programs are as following: Getting students,

1. Adopt a habit and pleasure of reading; helping them to develop their aesthetic taste.

2. Memorize poems and proses which they like.

3. Adopt a habit of making choices among poems, joining in to the word choirs to animate these poems.

4. Get in the habit and pleasure of keeping a book of selected poems.

5. Improve, if existing already, oratory and poem reading skills in verbal art activities.

6. Obtain an ability to narrate, introduce a place, an event, person, or a living being, and to express thoughts and feelings about these persons/things (Turkish Program, 2002); having a strong sense of gratification and emotional 
discipline by getting in the habit of reasoning and thinking on the issues of language.

7. Comprehend the fineness of belief, information and taste in our culture; in this way educating and disciplining their feelings.

8. Turn their face towards the good and the beautiful, hence enabling them to get stronger through joy of living, self-confidence and good habits (Karakuş, 2000)

The texts in Turkish textbooks are primary sources for achieving the above mentioned targets. For this purpose, it is necessary to show utmost care in choosing the texts among the outstanding examples of each genre. It is necessary to abide by certain aesthetic criteria while choosing these samples. Taking into account the general characteristics of such aesthetic texts, we can point out these criteria as following:

\subsection{Using Elements of Figurative Language}

All artful sayings that writers and poets use in order to make their expressions more effective are called "figurative language". Since it is not possible to place here all elements of figurative language, we will only deal with most common ones: personification, simile, hyperbole, metaphor.

1.1.1 Personification: Personification means showing a non-living or living thing, other than human beings, as a person, who thinks, hears, and moves etc. (Dilçin, 2004).

1.1.2 Simile: It is the comparison made between two things that have some resemblance, essentially likening the one with inferior position in terms of the characteristics concerned to the one which is superior, with a view to making an expression stronger (Dilçin, 2004).

1.1.3 Hyperbole: Hyperbole is an intentional exaggeration of the properties of a thing in order to make an expression stronger, especially portraying it in such a situation that is impossible to happen (Dilçin, 2004).

1.1.4 Metaphor: It is a word or saying that is used totally in a different way from its original meaning due to a relationship or comparison (Turkish Language Institute, 1998)

\subsection{Establishing Connotation-meaning Infinity}

Connotation is the coming to the mind of one thought or image by appearance of another (Turkish Language Institution, 1998:423). Connotation-Meaning Infinity, on the other hand, can be defined as evoking different and personal meanings in the reader's mind by a word or sentence.

\subsection{Idioms}

In Turkish dictionary, idioms are defined as cliché expressions or sayings that are interesting but have more or less different meanings than its lexical origin (Turkish Language Institution, 1998)

\subsection{Aesthetic Elements of the Subject Matter}

The processing of the subject matter in an aesthetic way reflects the aesthetic value of the texts.

\subsection{Words evoking the concept of Aesthetics}

Placing words relating to "beautiful" and "the beauty" in the texts reflects the aesthetic value.

\subsection{Creating a Fictitious Text}

Transposing the text in the form of a story makes it more aesthetic, giving more pleasure to the reader, thus it can be a measure of aesthetic value.

\subsection{Cultural Base}

Culture encompasses all values of a society, material as well as spiritual. Giving cultural elements some space in the texts could create an aesthetic taste for the readers. Hence, creating a cultural base would reflect an aesthetic value. If texts that contain the elements mentioned above are chosen, it could be possible to raise/educate individuals with a well-developed taste for aesthetics.

\section{The Purpose of the Study}

The study aims at determining the aesthetic value of texts existing in the secondary school Turkish Textbooks and identifying the role of these texts in getting students adopt a taste for aesthetics.

\section{Method}

This is a quantitative research where document review technique is adopted. Document review comprises the analysis of written materials containing information on the phenomenon that is targeted to be investigated (Yıldırım and Şimşek, 2013). 


\section{Data Collection}

Data for the research were collected through the analysis, in accordance with the criteria for aesthetics, of one poem and one narrative which were randomly chosen from a textbook which was also randomly selected among the Turkish textbooks for each grade.

\section{Findings and Comments}

\subsection{Analysis of Texts in 5th Grade Turkish Textbook in Terms of Aesthetic Taste Criterion}

5.1.1 Aesthetic and Figurative Language Elements in the Poem: "Wind"

\subsubsection{Personification}

In the first verse, wind is personified with playing around: "Where does s/he played around" and in the third verse with climbing and herding: "Then s/he has started to climb/ herding the clouds like sheep". In third verse, wind is personified with these lines: "caressing the grasses in the plateaus/s/he has grown them up" by being thought as a person growing the grass by caressing them. With these lines in fourth verse: "If s/he has visited the villages/ $\mathrm{s} / \mathrm{he}$ must have rocked the cradles in the dark rooms", wind is personified by "rocking the cradles". Again in the fourth verse, it is personified by helping in the line "To those working under the sun/ s/he has helped" In the fifth verse, wind is personified with stopping by, passing and seeing in the following lines "S/he has passed by me as $\mathrm{s} / \mathrm{he}$ must have stooped by the cities/ s/he has seen girls like opium flowers" and with the ability to take and go away in the following line: "A smile, a strand of hair, blusher, powder/ s/he has taken them and gone away". In the sixth verse, it is personified with telling as in "S/he would have told, if I had asked/ I could not".

\subsubsection{Simile}

Clouds are resembled to sheep in the third verse: "Then s/he has started to climb/ herding the clouds like sheep". Girls are compared to opium flowers in the fifth verse: S/he has passed by me as s/he must have stooped by the cities/ s/he has seen girls like opium flowers".

\subsubsection{Hyperbole: No hyperbole is found in this poem}

\subsubsection{Metaphor: This poem does not include metaphors}

\subsubsection{Connotation-Meaning Infinity}

There are no expressions implying connotation-meaning infinity.

\subsubsection{Using Idioms}

The following idioms are used: "being at sixes and sevens" in the second verse, and "standing in the breach" in fourth verse.

\subsubsection{Aesthetic Elements}

The poem talks about the aesthetic beauty of the wind as being part of the nature.

\subsubsection{Words Evoking the Concept of Aesthetics}

"Heart", "caressing" and "flower" remind us of aesthetics.

\subsubsection{Creating a Fictitious Text}

Although the genre of the text is a poem, it can be considered as a fiction as it talks about the adventures of the wind.

\subsubsection{Cultural Base}

A cultural base is established in the poem as the village life and the hard work of the people under the sun are mentioned in the fourth verse while the characteristics of the people living there are given in the fifth verse.

\subsubsection{Aesthetic and Figurative Language Elements in the Story of "If the Forest Dries Up"}

\subsubsection{Personification}

In the second paragraph the village is personified with the expression: "our poor village, is an ill-fated village". In the second paragraph, flood is personified as: "We will stay here in the village and we will fight against the flood.

\subsubsection{Simile}

No art of simile is encountered in the text.

\subsubsection{Hyperbole}

The first paragraph exaggerates the damages of the flood: "A violent flood came in and took away anything that stood against it." 


\subsubsection{Metaphor}

"Getting angry, fitting well and fighting" are used metaphorically in the second paragraph.

\subsubsection{Connotation-Meaning Infinity}

In the text, there are no expressions pertaining to a connotation-meaning infinity.

\subsubsection{Using Idioms}

The following idioms are used in the text: "Shake the dust off one's feet", "his efforts going down the drain" (second paragraph) and "acknowledge someone to be right" (fourth paragraph).

\subsubsection{Aesthetic Elements}

Natural beauty and the benefits of the forest are mentioned in the context of aesthetics.

\subsubsection{Words Evoking the Concept of Aesthetics}

"Beautiful" (repeated two times) and "fitting well" evokes the idea of aesthetics in our minds.

\subsubsection{Creating a Fictitious Text}

As this is a text type-narrative, the events that take place as a result of the depletion of the forest are told in a fictitious way.

\subsubsection{Cultural Base}

The existence of the village between two mountains in a land full of greenery, gives us some hints about the village life, thus creating a cultural base.

\subsection{Analysis of Texts in 6th Grade Turkish Textbook in terms of Aesthetic Taste Criterion}

5.2.1 Aesthetic and Figurative Language Elements in Poem of "My Türkiye, My Türkiye"

\subsubsection{Personification}

In the following lines of the second verse: "You have Ararat, Toros Mountains/ all fighting with the wind", mountains are personified by being able to fight. In the fifth verse, Turkey is personified in these lines: "My pains will stop in your chest" and "My bones will be dissolved in your bosom" where it is shown as a person having body parts such as chest and bosom.

\subsubsection{Simile}

In the first verse Turkey is likened to a fire burning in the hearts: "Like a fire burning in the hearts". In second verse, the water resembles the gold: "Your Ceyhan and Seyhans (rivers) pour gold into the soil". In the fifth verse, heart is compared to a dining table: "Like his heart, his dining table is open to all country". In the sixth verse, Turkey is likened to be a home, happiness and a grave: "My Türkiye, my home, my happiness and my grave!" and to be bread, water and life "My bread, my water and my life".

\subsubsection{Hyperbole}

In the first verse, there is hyperbole since freedoms is shown as infinite: "My infinite freedom". In the fifth verse, the determination of doctors and engineers are exaggerated as if they were able to thrust through the mountains: "I saw many doctors and engineers/thrusting through the Mountain Raman". In the fifth verse, the courage of soldiers are exaggerated as if they were able to resist against death: "I saw lieutenants standing up against death"

\subsubsection{Metaphor}

The following words are used as metaphors in the poem: sensitive, shaking and burning in third verse; backwardness and sleep in fourth verse; "will be dissolved and scattered" in fifth verse; washed and burned in the sixth verse.

\subsubsection{Connotation-Meaning Infinity}

"My bones will be dissolved in your bosom" in fifth verse and "washed with bloods of the martyrs" reflect a connotation-meaning infinity.

\subsubsection{Using Idioms}

The following expressions are used as idioms: "To knuckle under" in third verse; and "to stand sentinel" and "to resist against" in the fifth verse.

\subsubsection{Aesthetic Elements}

Historical and natural beauties of Turkey are presented in an aesthetic way. 


\subsubsection{Words Evoking the Concept of Aesthetics}

"Love, hear and happiness" remind us of aesthetics.

\subsubsection{Creating a Fictitious Text}

Although the genre of the text is poetry, it can be considered as a fiction as it presents different life situations faced by different people in different parts of Turkey.

\subsubsection{Cultural Base}

The poem establishes a cultural base by telling about legends in the first verse and about the flag as a heritage from our forefathers.

5.2.2 Aesthetic and Figurative Language Elements in the Story of "Storks"

\subsubsection{Personification}

In the first paragraph, spring is personified with its ability to breathe: "He has felt the breath of the spring inside." In the seventh paragraph, storks are personified as if they are in a hurry: "Storks were in a hurry to build their homes". In the twenty-first paragraph, storks are enjoying doing something: "They must have been enjoying their new homes after a long tiredness."

\subsubsection{Simile}

In the second paragraph, the news of storks' coming is likened to a secret. "He wanted to keep their coming like a secret". Again in the same paragraph, this news is resembled to an evangel: "He run and told his father this news like an evangel." In sixth paragraph, the kid is compared to a feather: "Strong hands of the warden threw him to the sky like a feather." In the eighteenth paragraph, birds are compared to waves in the sea: "Rather than birds, they were resembling the waves in the sea riding white foams. Storks are likened to water in twenty-sixth paragraph: "He saw storks in this dream that night. They were flowing into the depths of the sky like water." In the twenty-seventh paragraph, inner world of the kid is compared to a dirty sky: "His inside was like a dirty sky, without storks." The traces of his nose on the window's glass is compared to a finger stamp in paragraph twenty-eight: "Traces of his nose were on the window again, embroidered like a finger stamp".

\subsubsection{Hyperbole}

In the seventh paragraph, storks are described in an exaggerated way: "a sky full of storks".

\subsubsection{Metaphor}

The following words are used metaphorically: "did not get fire" in paragraph three; "let things slide" in eleventh paragraph; "broken" in the seventeenth paragraph; "“suddenly burned out inside him/her" in twenty seventh paragraph.

\subsubsection{Connotation-Meaning Infinity}

There are expressions implying connotation-meaning infinity: in paragraph three, "It seemed as if there was warmth that had slimed to her wings while passing through cruelly long roads of the south and in twenty seventh paragraph: "There were not even those storks who had taken and brought the spring under their wings".

\subsubsection{Using Idioms}

The following idioms are used in the text: 19th paragraph: "to come to his senses", "to catch his eyes" and "to get a kick out of it" 22nd paragraph: "to suck up" 26th paragraph: "to give up all hope" "to take revenge" and "to take heart".

\subsubsection{Aesthetic Elements}

Natural beauties of the storks and the spring are mentioned in the text.

\subsubsection{Words Evoking the Concept of Aesthetics}

Love, excitement (three times), evangel, being delighted (twice), enthusiasm, joy (three times), embroidered are words which are reminiscent of the aesthetics.

\subsubsection{Creating a Fictitious Text}

The situation faced by storks is presented in a fictitious way in the story.

\subsubsection{Cultural Base}

In the nineteenth paragraph there is a reference to an inauguration ceremony, hence describing a cultural base: "They are a marching band, said his mother, the factory will be inaugurated" 


\subsection{Analysis of Texts in 7th Grade Turkish Textbook in terms of Aesthetic Taste Criterion}

5.3.1 Aesthetic and Figurative Language Elements in the Poem of "the Rooms and the Sofas"

\subsubsection{Personification}

In the third verse, loneliness is personified: "Steps of the loneliness/ are heard in the sofa". In the fourth verse, room is personified: "The room can hear inside/ the ones falling from the gutter." Again in the fourth verse, sofa is personified as being able to listen: "Drilling the night, Sofa/ listens to the stairs." Stairs are also thought to be as persons listened by sofa, thus personified as well. Sofas are also personified in the sixth verse for not sleeping: "The sofas that are not sleeping."

\subsubsection{Simile}

In the first verse, houses are likened to the pomegranates and the sofas to the pomegranate arils: "Houses look like pomegranates/ and sofas like their arils". In the same verse, night is compared to a road and tranquility to the water: "Night travels around like a road/ and tranquility fills in like water" In the second verse, sun is compared to an ember burning in the windows "Of the ember burning in the windows" and in fifth verse, roam is compared to a bird: "my room collects like a bird" Again in the fifth verse, words of the sofa are likened to a bibelot: "words of my sofa / like a bibelot". The poet likens himself to the sand: "... crumbles me / like sand all along the wall" in the sixth verse.

\subsubsection{Hyperbole}

The excesses of the shadow are exaggerated in the third verse: "Stacked in the room/ bunches of shadow"

\subsubsection{Metaphor}

The following words are used metaphorically in the text: "filling" (First verse) "falling inside me" (second verse) and "drilling" (fourth verse)

\subsubsection{Connotation-Meaning Infinity}

By using the expression of "bunches of shadow, connotation-meaning infinity is achieved.

\subsubsection{Using Idioms}

No idiom is found in the poem.

\subsubsection{Aesthetic Elements}

The internal and external properties of rooms and sofas are discussed in an aesthetic fashion.

\subsubsection{Words Evoking the Concept of Aesthetics}

"Bibelot" and "decorating" are word reminding us of aesthetics.

\subsubsection{Creating a Fictitious Text}

Although the genre of the text is poem, it is given in a fictitious way through personification of rooms and sofas.

\subsubsection{Cultural Base}

Characteristics of old houses are described, properties of sofas, blinds etc. are mentioned, thus a cultural base is established in the poem.

5.3.2 Aesthetic and Figurative Language Elements in the legend of "Bursa"

\subsubsection{Personification}

There is no element of personification in the text.

\subsubsection{Simile}

In the fifth paragraph, girl's hair is likened to gold, her skin to the quince and her lips to the ruby: "the girl with golden hair, pale-skinned like a quince, red-lipped like a ruby" In the fifteenth paragraph, the sound is compared to moaning: "Meanwhile, a sound is heard like a deep-touching moaning".

\subsubsection{Hyperbole}

Arrival of the water is exaggerated in the eighteenth paragraph: "Rocks are cracked, stones thrown away; babbling water, millions of foams, not possible to stand in front."

\subsubsection{Metaphor}

The following words/expressions are used metaphorically in the text: in the third paragraph: "has won"; in sixth paragraph: "to which it is wrapped", "dragging" and "finding tranquillity", in eight paragraph: "being cut" and "being 
'broken”, fifteenth paragraph: "touching” and eighteenth paragraph: "melted”.

\subsubsection{Connotation-Meaning Infinity}

No word is found to be expressing connotation-meaning infinity.

\subsubsection{Using Idioms}

The following idioms are used in the text: in the first paragraph: "finding his/her tongue" and "giving orders"; in fourth paragraph: "champing at the bit"; in fifth paragraph: "not sleeping a wink", in sixth paragraph: "shedding blood", in seventh paragraph "passing away", in eight paragraph: "dig in one's heel" and "not laying a finger on", in ninth paragraph "bowing to the inevitable".

\subsubsection{Aesthetic Elements}

The history and the natural beauties of Bursa are depicted in an aesthetic way.

\subsubsection{Words evoking the Concept of Aesthetics}

“Heaven (two times), beautiful (four times), beauty (two times), lover (two times), titivate and admirer' evoke aesthetics

\subsubsection{Creating a Fictitious Text}

A legend on the origin of the name "Bursa" is presented in a fictitious setting.

\subsubsection{Cultural Base}

References to H. H. Suleyman in the first paragraph and to Orhan Gazi in third paragraph lay down a cultural base for the text.

\subsection{Analysis of Texts in 8th Grade Turkish Textbook in terms of Aesthetic Taste Criterion}

5.4.1 Aesthetic and Figurative Language Elements in the poem of "Sidewalks"

\subsubsection{Personification}

In the first verse, a street is personified as being abandoned: "I'm in a street, in the middle of an abandoned street". In the second verse, lightning is personified with watching: "The chimneys of houses are watched by lightings" and sidewalks for being vagrant: "One is me, and the other is vagrant sidewalks" In the fourth verse, sidewalks is personified as being a mother and as a living person: "Sidewalks, the mother of lonely sufferers/Sidewalks, is a human who lives in me". In the fifth verse, sidewalks is again personified as a mother: "I'm the child, breastfed by the sidewalks". In the sixth verse, the road is personified with the ability to walk: "Let me go as the road goes". The sidewalks is personified as having a partner: "I wish dies, this lovesick partner of sidewalks."

\subsubsection{Simile}

In the third verse, houses are compared to a man whose eyes are blinded: "Houses, like a blind man whose eyes were branded with hot iron" In the fifth verse, poet likened himself to a child: "child, breastfed by the sidewalks". In the sixth verse, lamps were compared to flood: "Let lamps flow from my sides as a flood". In the sixth verse, gloom is likened to an arch "Let there be an arch, vaulted in gloom, on my way" while in the seventh verse, darkness is compared to a "damp quilt: "As in a damp quilt let me wrap myself here / Cover me, cover me in their cool darkness" In the eight verse, stones resemble ice: "If these cold stones like ice would draw the fever from my brow" and streets are likened to a drowse: "Like these streets plunging into uncanny drowse".

\subsubsection{Hyperbole}

The poet exaggerates his fear in the third verse: "Drop by drop a terror collects in me at the head of every street the demons wait"

\subsubsection{Metaphor}

The following words/expressions are used metaphorically: "the point mingled" (first verse); drop by drop terror collects in me" (third verse); "give up" and "soft" (fifth verse) and "flow" (sixth verse).

\subsubsection{Connotation-Meaning Infinity}

Connotation-meaning infinity is expressed in the following words: "At the point my path is mingled with the black" (first verse); "Drop by drop a terror collects in me" (third verse); "Sidewalks, a language within me lingering"

\subsubsection{Using Idioms}

In the fifth verse, "giving up life" is used as an idiom. 


\subsubsection{Aesthetic Elements}

Internal and external properties of sidewalks are presented in an artistic manner.

5.4.1.8 Words evoking the concept of Aesthetics

Expressions of "Dreams" and "lovesick" remind us of aesthetics.

5.4.1.9 Creating a fictitious text

Although the text is a poem, it is told in a fictitious way with many similes, metaphors and personification of sidewalks.

5.4.1.10 Cultural Base

By having a reference to the lovesick persons in the eighth verse, a cultural base is established in the poem.

5.4.2. Aesthetic and Figurative Language Elements in the Story of "the Guarantor"

\subsubsection{Personification}

No personification is found in the text.

\subsubsection{Simile}

In the tenth paragraph walking is compared with running "He was walking on the road as if he were running"

5.4.2.3 Hyperbole

No hyperbole is seen in the text.

\subsubsection{Metaphor}

The following words are used metaphorically: "heavy" (first paragraph); "dependence" (third paragraph), "whipped" (thirteenth paragraph), "let me share" (fourteenth paragraph), "let him throw away" (fifteenth paragraph).

\subsubsection{Connotation-Meaning Infinity}

No words are found in the texts expressing connotation-meaning infinity.

\subsubsection{Using Idioms}

The following idioms are used in the text: "Giving no respite, going up against" (first paragraph); "going down on his/her knees" (third paragraph); "beg his/her pardon" (seventh paragraph); "keeping his/her promise" (eight paragraph); betaking himself/herself to; laying down his/her arms" (ninth paragraph); "hitting the roads" (tenth paragraph); "letting himself/herself go; taking someone to the gallows" (twelfth paragraph), "making fun of; giving up his/her hopes" (thirteenth paragraph).

\subsubsection{Aesthetic Elements}

Friendship and self-sacrifice are discussed often by making reference to related idioms.

\subsubsection{Words Evoking the Concept of Aesthetics}

The following words evoke the idea of aesthetics in the text: beautiful (three times), happy (two times), love, and heart.

\subsubsection{Creating a Fictitious Text}

"Friendship" is addressed in a fictitious setting in the story.

\subsubsection{Cultural Base}

The production and the life in the village are depicted hence a cultural base is established: "And those living in the village were unhappy. Whatever produced by the peasants were being taken away and those resisting this were being punished" (first paragraph).

As it is observed from the Table 1, the story, "If the forest dries up" is the text having the least number of aesthetic elements. On the other hand, the texts which are found to be the richest in terms of aesthetic taste are the legend of "Bursa" and the story of "Storks". These are followed by "My Türkiye, My Türkiye", a poem in 6th Grade textbook in third place and by "Sidewalks" a poem from 8th Grade textbook in fourth place. The most common elements are idioms and words/expressions evoking aesthetics, each criterion found 12 times, while "subject-matter", "fictitiousness of the text", "cultural base" and "connotation-meaning infinity" are least observed in the texts, with one appearance in each text on average. 
Table 1. Aesthetic Taste in the Texts, Frequency Scale

\begin{tabular}{|c|c|c|c|c|c|c|c|c|}
\hline \multirow[t]{2}{*}{ Aesthetic Taste Criteria } & \multicolumn{2}{|c|}{$5^{\text {th }}$ Grade } & \multicolumn{2}{|c|}{$6^{\text {th }}$ Grade } & \multicolumn{2}{|c|}{$7^{\text {th }}$ Grade } & \multicolumn{2}{|c|}{$8^{\text {th }}$ Grade } \\
\hline & $\stackrel{\square}{g}$ & 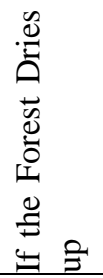 &  & $\frac{\mathscr{a}}{\bar{b}}$ & 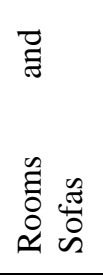 & 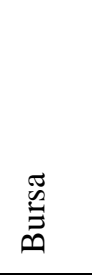 & $\begin{array}{l}\frac{n}{0} \\
\frac{0}{\pi} \\
\frac{0}{0} \\
\frac{0}{n}\end{array}$ & 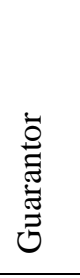 \\
\hline $\begin{array}{l}\text { 1.Using Elements of Figurative Language } \\
\text { 1.1.Personification }\end{array}$ & $\begin{array}{l}\text { Freq. } \\
8\end{array}$ & $\begin{array}{l}\text { Freq. } \\
2\end{array}$ & $\begin{array}{l}\text { Freq. } \\
3\end{array}$ & $\begin{array}{l}\text { Freq. } \\
3\end{array}$ & $\begin{array}{l}\text { Freq. } \\
5\end{array}$ & $\begin{array}{l}\text { Freq. } \\
0\end{array}$ & $\begin{array}{l}\text { Freq. } \\
7\end{array}$ & $\begin{array}{l}\text { Freq. } \\
0\end{array}$ \\
\hline 1.2.Simile & 2 & 0 & 5 & 7 & 6 & 4 & 7 & 1 \\
\hline 1.3.Hyperbole & 0 & 1 & 3 & 1 & 1 & 1 & 1 & 0 \\
\hline 1.4.Metaphor & 0 & 3 & 10 & 5 & 4 & 8 & 8 & 5 \\
\hline 1.5.Connotation-Meaning Infinity & 0 & 0 & 2 & 2 & 1 & 0 & 3 & 0 \\
\hline 2.Using Idioms & 2 & 3 & 3 & 7 & 0 & 9 & 1 & 12 \\
\hline 3.Aesthetic Elements in the Subject & 1 & 1 & 1 & 1 & 1 & 1 & 1 & 1 \\
\hline 4.Words evoking the concept of Aesthetics & 3 & 3 & 4 & 9 & 2 & 12 & 2 & 7 \\
\hline 5.Creating a fictitious text & 1 & 1 & 1 & 1 & 1 & 1 & 1 & 1 \\
\hline 6.Cultural Base & 1 & 1 & 2 & 1 & 1 & 1 & 1 & 1 \\
\hline Total & 18 & 15 & 34 & 37 & 22 & 37 & 32 & 28 \\
\hline
\end{tabular}

\section{Results and Suggestions}

The result of our study can be summarized as following: Among the eight texts examined, the legend of "Bursa" from 7 th grade textbook and the story of "Storks", from 6th grade textbook, are the richest in terms of aesthetic criteria, while "If Forest Dries Up", from 5th grade textbook, is the poorest text in this respect. When we make a comparison between different grades, 5th grade textbooks have lowest number of aesthetic elements while such elements are more often observed in textbooks of 6th and 7th grades. All in all, it is concluded that, texts in Turkish textbooks are not sufficient in terms of aesthetic criteria.

Taking into account the results, it is possible to make the following suggestions:

1. Choosing appropriate texts for textbooks is very important for achieving specific targets. Therefore, due attention should be paid for choosing texts, for each genre, among the examples containing the criteria examined above at the highest level possible.

2. Texts which are considered to be poor in this respect should be taken out of textbooks. There is no doubt that, arrangement of additional work for teachers to determine the targets to be achieved in terms of aesthetics will contribute to the creation of a more productive educational setting.

3. The students can only choose and read aesthetic works only if their sense of aesthetics is developed well. This, on the other hand, is dependent upon reading a lot and having access to the finest samples of literary work in any language. To this end, students should be given the opportunity to meet the best works of Turkish literature in addition to the texts in their textbooks.

4. In order to help students adopt a more universal concept of the beauty, it is necessary to give place to classics and outstanding samples of foreign literature which are translated to our language.

\section{References}

Bozkurt, N. (1995). Theories of art and aesthetics. İstanbul: Sarmal Publications.

Dağlığlu, E. Ş. (2014). Primary education Turkish 7th grade textbook. Ankara: Cem Web Ofset Publications.

Dilçin, C. (2004). Understanding Turkish poetry with samples, Ankara: Turkish Language Institute Publications Primary Education Curriculum. (2002). Turkish-writing program 6-7-8. İstanbul: MEB (Ministry of Education) Publications.

İşcan, A., Efendioğlu, S., \& Ada, Ş. (2007). "The role of the literary texts in Turkish textbooks in providing students with aesthetic taste". Social Sciences Research Journal, 1:59-76.

Kaplan, Ş., \& Şen, Y. G. (2014). Primary education Turkish 6th grade textbook. Ankara: Gizem Publications. 
Kaplan, Ş., \& Şen, Y. G. (2014). Primary education Turkish 8th grade textbook. Ankara: Yıldırım Publications. Karakuş, İ. (2000). Teaching Turkish, Turkish language and literature. Ankara: Sistem Ofset Publications. Müftüoğlu, A., \& Bektaş, S. (2014). Primary education Turkish 5th grade textbook. İstanbul: FCM Publications. Turkish Language Institute. (1998). Turkish dictionary. Ankara: Turkish Language Institute Publications Yıldırım, A., \& Şimşek, H. (2013). Qualitative research in social sciences. Ankara: Seçkin Publications. 